
unrestricted re-use, distribution, and reproduction in any medium, provided the original work is properly cited.

doi: $10.1017 / \mathrm{S} 026719051700006 \mathrm{X}$

\title{
The Effects of Specific Learning Difficulties on Processes of Multilingual Language Development
}

\author{
JUDIT KORMOS \\ Lancaster University
}

\section{ABSTRACT}

This article reviews current research findings on how specific learning difficulties (SLDs) impact on the processes of multilingual language development. The review includes studies of young language learners in instructed classroom settings, as well as of multilingual children in second language (L2) contexts. Starting with a definition of the concepts of disability and SLDs, it next discusses the interaction of cognitive factors with first language (L1) and L2 literacy development and L2 learning. Also outlined are possible ways in which SLDs can be identified in different L2 learning contexts. A detailed analysis of how cognitive factors influence the development of L2 skills of young learners with learning difficulties is given in the last part of the article.

\section{INTRODUCTION}

In many contexts, communication skills in an additional language are just as essential as literacy and numeracy skills. Individual differences that impact on second language (L2) development have been widely researched within the field of second language acquisition, but until recently, the language learning processes of students with additional needs have received little attention (see, e.g., Kormos, 2017; Kormos \& Kontra, 2008; Kormos \& Smith, 2012). Specific learning difficulties (SLDs) not only influence the development of oral and literacy skills in children's first language (L1) but also have a great impact on the processes of L2 learning. Therefore, to ensure fair and equal opportunities in education for these learners, research needs to be done on how children with SLDs develop their L2 skills. Without an appropriate understanding of how children with SLDs acquire an additional language, it is impossible to design effective instructional programs. Furthermore, there is an acute need to develop valid and reliable tools to assess SLDs in multilingual children so that their early language and literacy development can be enhanced. In this review, I will first define the concepts of disability and SLDs. Next, I will discuss how cognitive factors interact with L1 and L2 literacy development and L2 learning, as well as the possible ways in which SLDs can be identified in different L2 learning contexts. Finally, I will describe how SLDs influence the processes of learning additional languages.

DEFINITIONS OF DISABILITY AND SPECIFIC LEARNING

\section{DIFFICULTIES}

Although in this article I use the term specific learning difficulties (SLDs), from a legal and educational perspective, SLDs constitute a type of disability. How we 
describe and label disabilities and the terminology we use not only reflect how we think about them, but they also influence our relationships with and behaviors toward people with disabilities. Deficit models of disabilities consider disabilities as deficiencies and a series of barriers in individuals' lives. The educational consequence of such models is that the main focus is on meeting children's individual needs (Thomas \& Loxley, 2007), and little attention is paid to how the children's environment itself creates barriers to successful learning. The interactional view of disabilities (Frederickson \& Cline, 2002; Norwich, 2009) highlights the belief that disabilities hinder full participation in society because individuals' impairments interact with barriers in the environment. Taking this perspective can allow L2 researchers to not only describe the strengths and weaknesses of young language learners and multilinguals who have SLDs, but also investigate the intricate interactions between individuals and their contexts.

The labels used to describe SLDs vary greatly across contexts, and even within contexts, depending on whether SLDs are studied in psychology or education. In the 5th edition of the Diagnostic and Statistical Manual of Mental Disorders (DSM-5; American Psychiatric Association [APA], 2013) the label specific learning disorder is used. In psychological research and legislation in Canada, Australia, and the United Kingdom, the terms learning disability and learning difficulty are in use. The labels learning disorder and learning disability are appropriate within biological, medical, and psychological frameworks where researchers aim to uncover the exact nature and cause of SLDs. In the field of education in the United Kingdom, individuals are often described as having specific learning differences, which reflects the view that if institutions met the differing needs of students, these learning differences would lose their relevance. (This differentiation in terminology, however, does not affect educational provision because it is regulated by the legal requirements of different countries.) I would argue that the term learning difficulty reflects an interactionist position and might serve our field best, given that we want to understand how individual children's characteristics and barriers in the educational system jointly influence processes of multilingual language development.

SLDs can be defined and characterized in multiple ways depending on the specific field of research and whether one aims to describe them on the biological, cognitive, behavioral, or environmental levels (for a detailed review, see Kormos, 2017). For the purposes of this article, I will adapt the definition of the DSM-5 (APA, 2013) because it is the most recent conceptualization and the best empirically grounded. The novelty of characterizing SLDs in the DSM-5 is that it groups various subtypes of SLDs, such as dyslexia and dyscalculia (mathematics disability), under a joint umbrella term of SLDs. This acknowledges the large overlap between these types of learning difficulties. Yet it also creates subcategories of SLDs, two of which are particularly relevant for multilingual children: "specific learning disorder in reading" and "specific learning disorder in written expression." Within the category of SLDs in reading, the DSM-5 distinguishes word-level decoding problems as "dyslexia" and higher-level text comprehension problems as "specific reading comprehension impairment" (Cain, Oakhill, \& Bryant, 2004). SLDs in 
writing comprise problems with spelling, punctuation and grammatical accuracy, and clarity and organization of written expression. Due to limitations in length and the fact that most previous research has investigated reading-related SLDs, these types of SLDs will be my primary focus in this article.

The definition of SLDs in the DSM-5 (APA, 2013) is based on the processing strengths and weaknesses framework (Hale et al., 2010), which emphasizes uncovering specific problems that cause difficulties in learning. As its name suggests, the framework recognizes that individuals have various strengths and weaknesses, and it advocates that interventions are matched to individual profiles. In the case of SLDs, the manual highlights underlying weaknesses in the areas of working memory, executive functioning (planning, organizing, strategizing, and paying attention), processing speed, and phonological processing. The diagnostic criteria stipulate that observable difficulties in learning need to be present for at least 6 months despite targeted intervention. Importantly, the criteria also state that difficulties in academic performance might not always be observable in early school years and might become apparent in later years when academic demands become higher. As with any manual aiming to facilitate diagnosis, the DSM-5 states that "affected academic skills are substantially and quantifiably below those expected for the individual's chronological age" (APA, 2013, p. 67).

\section{INTERRELATIONSHIP OF COGNITIVE FACTORS IN LI AND}

\section{2 LITERACY DEVELOPMENT AND L 2 LEARNING}

The study of SLDs in the field of second language acquisition is important not only because a large proportion of multilingual children exhibit signs of SLDs, but also because, through research on SLDs, we can gain important insights into cognitive factors that can influence development in additional languages. Evidence accumulated over the past 25 years seems to lend support to Geva and Ryan's (1993) common underlying processes framework, which claims that key individual difference variables are responsible for predicting reading development in monolingual and multilingual children (for a review, see Geva \& Wiener, 2014). In similar vein, Sparks and Ganschow's (1993) linguistic coding differences hypothesis argues that the fundamental cognitive reasons for low achievement in additional languages are very similar to those that explain literacy-related difficulties in L1. The similarity of predictors of L1 and L2 reading outcomes and the strong link between L1 and L2 reading abilities can also be explained by universalist accounts of reading (Perfetti \& Harris, 2013). Although languages differ according to their scripts and the transparency of their orthographic systems-in other words, in how complex or simple sound-letter associations are-Perfetti, Zhang, and Berent (1992) have argued that phonological processing plays a central role in reading in all languages. Therefore, there seems to be key set of universal factors that influence the development of language and literacy skills in monolingual and multilingual children.

One of the most well-established hypotheses for the causes of reading difficulties in L1 is the phonological deficit hypothesis (Stanovich, 1988; Vellutino, 
1979), which attributes a central role to phonological-processing problems, more specifically to impaired phonological awareness. Difficulties with phonological awareness can be manifested at the level of syllabic knowledge (the ability to identify and manipulate syllables) and phonemic knowledge (the ability to divide words into sounds and to differentiate and manipulate sounds).

Although phonological-processing skills explain substantial variance in wordlevel decoding, there are other factors such as processing speed, working memory capacity, attention control, and ability to infer meaning that contribute to efficient word reading and to more complex, higher-order reading processes. One of these additional cognitive determinants of reading outcomes is naming speed (Lovett, Steinbach, \& Frijters, 2000; Wolf \& Bowers, 1999). Word-naming speed is a reflection of individuals' ability to access, activate, and phonologically encode appropriate lexical representations under time pressure. In order to execute these processes efficiently, one needs high processing speed and well-developed phonological and semantic lexical representations of words in the mental lexicon (Perfetti, 2007). Despite the central role of naming-speed measures in L1 literacy research (for a review, see Kirby, Georgiou, Martinussen, \& Parrila, 2010), their role in $\mathrm{L} 2$ reading is rarely investigated in the field of second language acquisition. Notable exceptions are two recent studies in which rapid automated naming (RAN) has been found to be a strong predictor of writing performance in young Finnish learners of English (Olkkonen, 2013) and Canadian English L2-speaking children (Harrison et al., 2016).

Another underlying cognitive ability that can influence word-decoding, and more importantly, higher-order reading comprehension in mono- and multilingual children is working memory ability, which includes both storage and processing capacity in short-term memory (Gathercole \& Baddeley, 1993). Working memory assists in keeping read information active, updating it with additional information, monitoring the comprehension of information, and drawing inferences based on background knowledge (Cain et al., 2004). Additionally, efficient control of attentional resources is also needed for monitoring comprehension, focusing on main ideas, and ignoring distractions. For this reason, central executive processes that regulate attentional resources and inhibit irrelevant information are also associated with reading outcomes (for a review, see Kendeou, van den Broek, Helder, \& Karlsson, 2014). Linck, Osthus, Koeth, and Bunting's (2014) meta-analysis indicates that verbal working memory and executive control have a strong relationship with L2 production and comprehension.

While the role of working memory capacity and executive control in reading comprehension is relatively stable across the life span and in different languages, the importance of two language-related abilities - phonological awareness and RAN - varies in different languages and depends on the age of the children. Phonemic awareness, that is, the ability to manipulate sounds, has been found to be a reliable predictor of word-level reading skills and dyslexia across a wide range of Indo-European and Finno-Ugric languages (e.g., Ziegler et al., 2010), Chinese (e.g., Wang, Georgiou, Das, \& Li, 2012), and Arabic and Hebrew (e.g., Abu-Rabia, Share, \& Mansour, 2003). Phonemic awareness, however, often 
becomes a less reliable or secondary predictor of word reading as children's reading skills develop, especially in transparent orthographies, that is, in languages with relatively simple letter-sound correspondences (Landerl et al., 2013). As children learn to read words more accurately, slow RAN can serve as a better indicator of reading difficulties than phonological awareness (Landerl \& Wimmer, 2008). In some languages, an additional language-related ability, morphological awareness (i.e., the ability to recognize and understand the use of parts of words that carry meaning) also influences word-level reading skills. Morphological awareness has been found to be a relevant predictor of dyslexia in Chinese (Chung \& Ho, 2009), Arabic (Saeigh-Haddad \& Geva, 2008), and Hebrew (Ravid \& Malenky, 2001).

As can be seen in the above overview, there is a large overlap among the basic cognitive factors that account for variations in L1 and L2 language and literacy outcomes. It is also widely known that L1 skills serve as important foundations for L2 development (Dufva \& Voeten, 1999; Koda, 2007). The question is then to what extent L1 and L2 learning difficulties overlap. Accumulating evidence seems to suggest that children with SLDs tend to experience difficulties in learning additional languages in instructed classroom and immersion contexts and in developing L2 literacy skills in English as a second language (ESL) contexts (see the discussion below).

Nevertheless, there is conflicting support for the assumption that at-risk or struggling L2 learners and readers also have difficulties in their L1 in college-aged populations (see e.g., Sparks, Javorsky, Ganschow, Pohlman, \& Patton, 1992; Sparks et al., 1998). Regarding children, Alderson, Haapakangas, Huhta, Nieminen, and Ullakonoja (2015) found that $15 \%$ of weak readers in English as an additional language were actually strong readers in their L1 Finnish in Grade 4 (aged 11). While none of the weak readers in English in Grade 8 (aged 15) were strong in Finnish reading, almost half of the students who scored low in L2 reading were in the medium range in both age groups. The L1 cognitive tasks that differentiated low and high English L2 reading ability groups were RAN in Grades 4 and 8 and word-list reading and nonword repetition in Grade 4. Ferrari and Palladino's (2007) research with Italian children aged 13 also suggests that L1 reading skills might not fully explain L2 performance in instructed classroom contexts. In the first phase of their study, low- and high-achieving English language learners did not differ significantly in L1 reading speed and accuracy, and students at risk of L2 learning difficulties did not meet the diagnostic criteria for dyslexic-type reading difficulties in their L1. These students, however, exhibited severe text-level reading comprehension problems in their L1. Erdos, Genesee, Savage, and Haigh's (2014) research in a Canadian immersion context, however, obtained different results from the previously described studies, where the L2 was taught as an additional language in the classroom. Their results indicated that early measures of L1 English skills, especially tests of phonological awareness and RAN, had very high precision (75$93 \%$ ) in predicting word-level and text-level reading comprehension problems of children in L2 French immersion.

The above findings suggest that low-achieving L2 learners, especially in instructed foreign language learning settings, might not always be at risk of, or 
diagnosed as having, SLDs. There are a number of possible explanations for this. First of all, children might have developed successful meta-cognitive strategies to overcome reading comprehension difficulties in their L1, but they might not be able to transfer these strategies to L2 reading (Alderson et al., 2015). Second, in languages that have transparent orthographies, such as Finnish and Italian, reading speed and accuracy measures in L1 might not be sensitive enough after the initial years of learning to read to detect subtle differences among children. Furthermore, Borodkin and Faust's (2014) research indicates that, in some cases, only highly specific phonological-processing tests can reliably distinguish low-achieving L2 learners and those with SLDs. They concluded that "L2 learning might be more vulnerable than $\mathrm{L} 1$ reading acquisition to subtle $\mathrm{L} 1$ phonological difficulties, as it involves a unique constellation of factors that create an additional burden on the phonological system" (p. 136). It is also important to note that cutoff points in any cognitive tests below which children are diagnosed as having an SLD are always somewhat arbitrary. The cognitive abilities described above are dimensional in nature and can be placed on a continuum. Children who score closely above cutoff points might miss identification in their L1, which does not, however, exclude the possibility that their cognitive-processing problems might cause difficulties in L2 development. Moreover, in addition to a direct effect, the cognitive determinants of L1 development might also influence ultimate L2 attainment indirectly through the mediation of L1 skills. One can hypothesize that there is an additive effect of reduced cognitive abilities, as they impede the development of L1 skills, which can then delay and slow down processes of second language acquisition. Finally, as a potential explanation for the lack of exact overlap between L1 and L2 learning difficulties, one should not forget that individuals' cognitive characteristics alone cannot account for L2 learning outcomes, because affective, social, and educational factors also play an important role in L2 development.

\section{ASSESSING AND IDENTIFYING LEARNING DIFFICULTIES \\ IN MULTILINGUAL AND INSTRUCTED CLASSROOM CONTEXTS}

A key question, particularly in multilingual education contexts, is how one can identify learning difficulties and distinguish them from lack of L2 proficiency. The issue is highly relevant for early identification of SLDs so that children will not miss out on opportunities for support and development and will not be inaccurately diagnosed as having an SLD. The aforementioned universalist perspective advocated by Geva and Ryan (1993) argues that a core set of individual difference variables, such as phonological awareness, RAN, working memory, and self-regulatory functions, explain literacy and general language-proficiency differences among monolingual and multilingual children. Based on this perspective, the solution to the problem of identification is the application of similar diagnostic instruments to those used for monolingual populations. If tests are available in children's L1, and one can assume that this language is indeed the child's dominant home language, SLDs 
can be identified using these L1 tools. In this situation, L2 learning problems can be predicted, but caution needs to be taken because, as I argue above, the lack of an official diagnosis of SLDs does not exclude the possibility of having L2 learning difficulties. In multilingual contexts, however, L1 test instruments might not be available or might not even exist, and for this reason, assessment tools in L2 are frequently used.

Tests in the children's L2 might have appropriate psychometric properties, but they are usually standardized for monolingual populations. A recent meta-analysis by Melby-Lervåg and Lervåg (2014) indicates that monolingual readers score significantly higher than bi/multilingual readers on tests of reading comprehension, and monolinguals also perform better in word-level reading tests. Research evidence also suggests that children perform worse in cognitive tests when the tests are administered in L2 than in their L1 (e.g., Alderson et al., 2015). If identification of SLDs is carried out using the same cutoff points as for monolingual children, learning difficulties might be overidentified (Samson \& Lesaux, 2009). Underidentification can also occur because teachers often assume that multilingual children perform below norms due to underdeveloped language proficiency and do not refer them to specialists for assessment (Limbos \& Geva, 2001).

A number of studies conducted in Canada indicate that for children who have had more than 2 years of schooling in L2, L2-based tests of phonological awareness, phonological short-term memory capacity, and RAN can reliably predict word-level decoding problems, that is, dyslexia (e.g., Geva, 2006; Geva \& Yaghoub Zadeh, 2006; Lesaux \& Siegel, 2003). These tests were found to be sensitive even when the children's oral language comprehension abilities in L2 were well below those of monolinguals. The findings in the UK context in research on younger children aged between 7 and 8 years by Everatt, Smythe, Adams, and Ocampo (2000) and older children (aged 10-12) by Frederickson and Frith (1998) indicate the suitability of L2 assessment tools for the identification of dyslexia in multilingual children. L2 tests used in the identification of text-level reading comprehension difficulties also proved to have high predictive value in Geva and MasseyGarrison's (2013) study in a Canadian multilingual context. Their results indicated that, regardless of language status, poor comprehenders could be characterized by a smaller range of vocabulary, a lower level of syntactic-processing skills, and difficulties with oral language comprehension and making inferences.

However, the issue of assessment for students who have limited proficiency in the L2 has not been resolved yet. Unfortunately, there is limited assessment research available for participants who have not had sufficient contact with the target language. In a recent project with adult learners, Elbro, Daugaard, and Gellert (2012) developed an assessment tool that was not specific to any particular language and which was found to be a good predictor of dyslexic-type word reading difficulties. In this test participants are asked to learn new sound-symbol correspondences (e.g., $*=/ \mathrm{d} /, \square=/ \mathrm{o} /, \boldsymbol{\uparrow}=/ \mathrm{g} /$ ) and then use this knowledge for reading two- and three-letter words (e.g., $\boldsymbol{*} \square \mathbf{\varphi}=/ \mathrm{dog} /$ ). Smith (2013) devised a similar comprehensive instrument, but to date there is no published research with younger multilingual populations using this tool. 
Another route often taken in the assessment of SLDs of L2 learners who have limited proficiency is the application of instruments in the students' L2. Several recent studies have examined how well cognitive and linguistic tests in the L2 can indicate word-level reading and reading comprehension difficulties of learners instructed in classroom settings. In Alderson et al.'s (2015) research, tests assessing working memory capacity, RAN, and phonological awareness, administered in English, proved to be reliable and strong predictors of reading comprehension difficulties of Finnish learners of English in both Grades 4 and 8. Erbeli and Pižorn's (2013) study with Slovenian children aged 13 also indicated that L2 assessment tools that are adapted to the students' level of proficiency can yield reliable information about reading problems in L2 English. A recent study by Bourgoin (2014) has shown that, in a French immersion context, some, but not all, assessment tests administered in L2 French, concomitantly with the start of French immersion, can predict children's word-level and reading comprehension difficulties. Tests of pseudo-word reading and French letter-naming were good indicators of L2 French reading outcomes, but phonological awareness in L2 French was not a reliable predictor in the first year of the immersion program. Bourgoin argued that lack of proficiency in the L2 might have hindered children performing the phoneme segmentation task. Nevertheless, she concluded that "students who need additional support in learning to read in the L 2 can be identified using early literacy indicators, both in their L1 (administered before L2 learning) and in their L2 (administered concurrently to L2 learning)" (p. 376).

There are several important conclusions one can draw from available research findings on the assessment of SLDs of multilingual children and language learners in instructed and immersion classroom settings. First, the available evidence suggests that it is wrong to assume that the assessment of SLDs is impossible for children who are not fully proficient in the L2 (for a comprehensive discussion of this issue, see Geva \& Wiener, 2014). As the aforementioned studies indicate, even in the case of children who have had limited exposure to the target language in classroom settings, cognitive tests administered in the L2 can yield relevant information. Second, a combination of L1 and L2 assessment tools is recommended (see Alderson et al., 2015) in order to gain a comprehensive overview of students' difficulties. Third, more research effort should be concentrated on developing testing instruments that require children to work with linguistic material that is not specific to any particular language. The results of such tests could be normed and standardized and then be applied in contexts where cutoff points for making decisions are needed for diagnostic, pedagogic, or legislative purposes. Finally, it is important to conduct more longitudinal research on how predictors of the reading difficulties of multilingual children and language learners change with age, and with development of proficiency. Studies in the field of L1 reading suggest that in the initial stages of reading development, children rely on their word-level decoding skills to comprehend written texts. As their word-level reading skills develop and become automatic, general language comprehension abilities gain in importance (Geva \& Farnia, 2012). Therefore, predictors of literacy-related difficulties of children are also likely to change. One 
of the few studies available to date, by Farnia and Geva (2013), suggests that L2 reading development is nonlinear, and although phonological awareness, naming speed, and working memory are important early contributors to reading comprehension outcomes, when assessed in Grade 4, they no longer explain individual variations in reading comprehension outcomes. Instead, phonological short-term memory becomes a significant contributor to reading comprehension outcomes in later years.

EFFECTS OF SLDS ON LEARNING ADDITIONAL

LANGUAGES

As discussed above, children with SLDs tend to have lower working memory capacity and reduced phonological and morphological awareness, and they might experience difficulties processing linguistic input and output under time pressure. Therefore, it is reasonable to assume that due to their differential cognitive functioning, they might be less efficient in developing their L2 skills. To illustrate, one important cognitive ability that is impaired in children with SLDs is working memory. Working memory abilities were traditionally assumed to be influential in explicit learning, but not in implicit and incidental learning processes (e.g., Reber, Walkenfeld, \& Hernstadt, 1991), which are by-products of other cognitive operations and less prone to the influence of individual differences (Unsworth \& Engle, 2005). Nonetheless, recent work in the field of cognitive psychology indicates that working memory operations might be involved in implicit learning processes (Hassin, Bargh, Engell, \& McCulloch, 2009) and children with dyslexia show reduced ability to learn new skills implicitly (Stoodley, Harrison, \& Stein, 2006). Research on the implicit L2 learning processes of children with SLDs is scarce. Information is only available through interviews conducted with language learners with an official diagnosis of SLD in Hungary (Kormos \& Mikó, 2010). The participants in this research gave accounts of their experiences of when they found it challenging to extract patterns and regularities for grammar in implicit learning conditions, and they expressed a preference for explicit explanations of syntax, morphology, and spelling.

SLDs also influence the processing of written and spoken input for comprehension and subsequent L2 learning. One way of accessing input for learning is through reading. As described above, reduced phonological awareness and difficulties with rapid word naming might lead to L2 word-decoding problems. Difficulties in comprehending longer texts can result from either word-level reading problems or from a global language comprehension deficit (Geva \& Massey-Garrison, 2013). The reduced working memory capacity of children with SLDs might also hinder comprehension by limiting the number of verbal units (L2 phonemes, morphemes, words, clauses) they can remember while reading a text (see, e.g., Abu-Rabia $\&$ Siegel, 2002). A certain level of comprehension of texts and automaticity in lower-level decoding skills is a prerequisite for L2 development through exposure. If understanding breaks down and children's attentional resources are taken up 
in low-level decoding, they will find it difficult to notice and understand novel grammatical constructions and lexical items in the input.

Children with SLDs have been found to experience difficulties in L2 reading in a variety of learning contexts. Both Norwegian (Helland \& Kaasa, 2005) and Hungarian children with SLDs (Kormos \& Mikó, 2010) performed worse on a test of L2 English word reading than their nondyslexic peers. Hungarian children with SLDs also scored significantly lower on a sentence comprehension test than their peers matched for age (Kormos \& Mikó, 2010). In a Canadian English as an additional language context, Geva, Wade-Woolley, and Shany's (1993) study obtained similar results. Crombie's (1997) findings with Scottish primary and secondary schoolchildren learning French also constitute strong evidence of the L2 reading comprehension difficulties of children with SLDs. Sparks and Ganschow (2001) found that L2 word-decoding skills were often associated with L2 learning difficulties in Spanish as a foreign language in a high school context in the United States. Hungarian children with a formal diagnosis of dyslexia reported substantial difficulties with reading comprehension in either German or English as an L2. This indicates that even reading in German with its relatively transparent orthography causes challenges for language learners with SLDs.

Another important source of input for L2 development is exposure to spoken texts. The nature of challenges that children with SLDs face in comprehending orally presented information varies depending on their phonological-processing skills, phonological short-term memory, and language comprehension ability. In a Canadian context, L2-speaking children who demonstrated general language comprehension difficulties performed significantly worse in a test of listening comprehension than children who had no such difficulties and children who had wordlevel decoding problems, that is, dyslexia (Geva \& Massey-Garrison, 2013). Young dyslexic English language learners in Norway and Hungary also scored at similar levels to their nondyslexic peers in a test of sentence-level listening comprehension (Helland \& Kaasa, 2005; Kormos \& Mikó, 2010). Crombie's (1997) study, however, revealed significant differences in listening comprehension between dyslexic and nondyslexic Scottish schoolchildren learning French. The evidence to date seems to suggest that, in most contexts, children whose general language comprehension skills are not impaired, and who might only have word-level decoding problems, might be as successful in comprehending oral L2 texts as their peers with no SLDs. Therefore, these children might face fewer challenges in acquiring L2 knowledge incidentally through exposure to oral texts than through reading.

Children with SLDs often find it difficult to acquire new knowledge, not only incidentally but also intentionally. To illustrate, both language learners with SLDs and their teachers report children with SLDs need a high number of encounters and many practice activities so that they can remember new words (Sarkadi, 2008). Their difficulties in committing L2 words to long-term memory are associated with their reduced phonological short-term memory capacity (Service, 1992; Service \& Kohonen, 1995). Phonological short-term memory has been found to play an important role in the learning of form-meaning associations and to assist in "forming stable long-term representations of novel phonological material" (Martin 
\& Ellis, 2012). Phonological short-term memory and working memory are also strongly related to children's ability to infer grammatical regularities and apply these productively (Martin \& Ellis, 2012), which also explains the difficulties many children with SLDs might face in the acquisition of L2 grammar. In a study with young Hungarian English language learners, Kormos and Mikó (2010) found that children who had an official diagnosis of dyslexia scored significantly below the level of their age-matched nondyslexic peers in a test of L2 grammatical knowledge. Their results also revealed that the gap in performance between dyslexic and nondyslexic children widened as the grammatical constructions increased in difficulty. In a questionnaire study, Hungarian dyslexic children also reported high levels of difficulty with L2 grammar (Kormos \& Mikó, 2010).

Children with SLDs not only find it challenging to acquire L2 comprehension skills, but they also face difficulties with productive skills, especially L2 writing. Reduced working memory and phonological awareness are key cognitive characteristics that can account for the difficulties of L2 writers who have SLDs. L2 writing requires the careful orchestration of composing and linguistic encoding processes and is highly taxing on attentional and working memory resources (Schoonen, Snellings, Stevenson, \& van Gelderen, 2009). Research in a Canadian context confirms that children with SLDs struggle with lower-level writing processes, such as spelling, punctuation, and the monitoring of syntax (Ndlovu \& Geva, 2008). These children also experience difficulties "with higher level aspects of writing such as sentence structure constraints and the generation and coordination of vocabulary, as well as with aspects of the overall structure of their compositions including the ability to compose stories with interesting plots and story lines" (Ndlovu \& Geva, 2008, p. 55). In another context, Crombie (1997) also found that young learners of French in Scotland who had an official diagnosis of dyslexia scored below their peers in a test of writing. A number of studies indicate that the spelling skills of young English language learners with SLDs are also below those who do not have an SLD (Helland \& Kaasa, 2005; Ndlovu \& Geva, 2008; Kormos \& Mikó, 2010). Spelling difficulties also persist among young learners of L2 German, despite the more transparent nature of the orthography of German than English (Kormos \& Mikó, 2010).

In certain contexts, the oral L2 language production skills of children with SLDs have been found to be at the same level as their peers. In Norway, where there is abundant L2 English exposure through various electronic media, Helland and Kaasa (2005) found that the oral performance of children with SLDs did not differ from those who had no SLDs. In Hungary (Kormos \& Mikó, 2010) and Scotland (Crombie, 1997), where less input and fewer opportunities for the communicative use of target languages (English and French, respectively) are available, children with SLDs had significantly lower oral performance scores than those with no SLDs. The difference between the Norwegian findings and those obtained in Hungary and Scotland might be related to the fact that Hungarian and Scottish learners had fewer opportunities to automatize speaking skills.

In addition to cognitive abilities, and often in a complex interaction with them, affective factors also exert a significant influence on the processes of second 
language acquisition. Motivation, language learning anxiety, self-confidence, and self-esteem are among these affective factors that are particularly relevant in relation to young learners with SLDs. As shown above, children with SLDs might have considerable difficulties in L2 learning, and consequently, their motivation might decrease (Kormos \& Csizér, 2010) while their language learning anxiety might increase (Piechurska-Kuciel, 2008). In a questionnaire survey, young Hungarian learners of English and German with an official diagnosis of dyslexia reported considerably lower levels of motivation and more negative attitudes to language learning than their nondyslexic peers (Kormos \& Csizér, 2010). The results of the survey also showed that the children had a negative self-concept in the domain of language learning. In an interview study, Csizér, Kormos, and Sarkadi (2010) demonstrated that the language learning motivation of students with SLDs shows large fluctuations within relatively short time intervals, due to the influence of external (e.g., peers' and teachers' classroom behavior and attitudes to SLDs and accommodations) and internal factors (e.g., goals and effort). Their study also showed that learners' immediate environment and the instructional setting has a significant impact on learning goals, attitudes, and motivated behavior, with teachers' general in-class behavior, methods of instruction, and attitudes toward SLDs playing a particularly strong role.

\section{CONCLUSION}

This article has reviewed the current standing of research on the language learning processes of children with SLDs. The available research to date yields insights into the cognitive, motivational, and affective characteristics of "average" L2speaking children and the challenges they face in developing their L2 competence. However, we have limited understanding of how varied children with SLDs are and how they develop and change longitudinally. In addition, little is known about how motivational, affective, and cognitive factors, and instructional contexts interact with each other and influence L2 development. Further in-depth qualitative and large-scale quantitative and experimental studies could help us understand these complex interactions better. Nonetheless, there is ample evidence to be convinced that, with adequate support and in inclusive environments, children with SLDs can become successful multilingual language users, and there is no reason why they should be excluded and discouraged from learning additional languages in any context (Genesee \& Fortune, 2014; Kormos, 2017).

\section{REFERENCES}

Abu-Rabia, S., Share, D., \& Mansour, S. M. (2003). Word recognition and basic cognitive processes among reading-disabled and normal readers of Arabic. Reading and Writing: An Interdisciplinary Journal, 16, 423-442.

Abu-Rabia, S., \& Siegel, L. S. (2002). Reading, syntactic, orthographic and working memory skills of bilingual Arabic-English speaking children. Journal of Psycholinguistic Research, 31, 661-678.

Alderson, J. C., Haapakangas, E.-L., Huhta, A., Nieminen, L., \& Ullakonoja, R. (2015). Diagnosing reading in a second or foreign language. London, UK: Routledge.

American Psychiatric Association (APA). (2013). Diagnostic and statistical manual of mental disorders (5th ed.). Arlington, VA: Author. 
Borodkin, K., \& Faust, M. (2014). Native language phonological skills in low proficiency second language learners. Language Learning, 64, 132-159.

Bourgoin, R. (2014). The predictive effects of L1 and L2 early literacy indicators on reading in French immersion. Canadian Modern Language Review, 70, 355-380.

Cain, K., Oakhill, J., \& Bryant, P. (2004). Children's reading comprehension ability: Concurrent prediction by working memory, verbal ability, and component skills. Journal of Educational Psychology, 96, 31-42.

Chung, K. K. H., \& Ho, C. S. H. (2009). Second language learning difficulties in Chinese children with dyslexia: What are the reading-related cognitive skills that contribute to English and Chinese word reading? Journal of Learning Disabilities, 43, 194-211.

Crombie, M. (1997). The effects of specific learning difficulties (dyslexia) on the learning of a foreign language at school. Dyslexia, 3, 27-47.

Csizér, K., Kormos, J., \& Sarkadi, Á. (2010). The dynamics of language learning attitudes and motivation: lessons from an interview study with dyslexic language learners. Modern Language Journal, 97, 470-487.

Dufva, M., \& Voeten, M. (1999). Native language literacy and phonological memory as prerequisites for learning English as a foreign language. Applied Psycholinguistics, 20, 329-348.

Elbro, C., Daugaard, H. T., \& Gellert, A. S. (2012). Dyslexia in a second language? A dynamic test of reading acquisition may provide a fair answer. Annals of Dyslexia, 62, 172-185.

Erbeli, F., \& Pižorn, K. (2013). Assessment accommodations in EFL reading competence for Slovene EFL students with specific reading differences. In D. Tsagari \& G. Spanoudis, (Eds.), Assessing L2 students with learning and other disabilities (pp. 189-206). Newcastle upon Tyne, UK: Cambridge Scholars.

Erdos, C., Genesee, F., Savage, R., \& Haigh, C. (2014). Predicting risk for oral and written language learning difficulties in students educated in a second language. Applied Psycholinguistics, 35(2), 371-398.

Everatt, J., Smythe, I., Adams, E., \& Ocampo, D. (2000). Dyslexia screening measures and bilingualism. Dyslexia, 6, 42-56.

Farnia, F., \& Geva, E. (2013). Growth and predictors of change in English language learners' reading comprehension. Journal of Research in Reading, 36, 389-421.

Ferrari, M., \& Palladino, P. (2007). Foreign language learning difficulties in Italian children: Are they associated with other learning difficulties? Journal of Learning Disabilities, 40, 256269.

Frederickson, N., \& Cline, T. (2002). Special educational needs, inclusion and diversity: A textbook. Maidenhead, UK: Open University Press.

Frederickson, N., \& Frith, U. (1998). Identifying dyslexia in bilingual children: A phonological approach with inner London Sylheti speakers. Dyslexia, 4, 119-131.

Gathercole, S., \& Baddeley, A. D. (1993). Working memory and language (Essays in cognitive psychology). Mahwah, NJ: Erlbaum.

Genesee, F., \& Fortune, T. (2014). Bilingual education and at-risk students. Journal of Immersion and Content-based Language Education, 2, 196-209.

Geva, E. (2006). Second-language oral proficiency and second-language literacy. In D. August \& T. Shanahan (Eds.), Developing literacy in second-language learners: Report of the National Literacy Panel on language-minority children and youth (pp. 123-140). Mahwah, NJ: Erlbaum.

Geva, E., \& Farnia, F. (2012). Developmental changes in the nature of language proficiency and reading fluency paint a more complex view of reading comprehension in ELL and EL1. Reading and Writing, 25, 1819-1845.

Geva, E., \& Massey-Garrison, A. (2013). A comparison of the language skills of ELLs and monolinguals who are poor decoders, poor comprehenders or normal readers. Journal of Learning Disabilities, 46, 387-401.

Geva, E., \& Ryan, E. B. (1993). Linguistic and cognitive correlates of academic skills in first and second languages. Language Learning, 43, 5-42.

Geva, E., \& Wiener, J. (2014). Psychological assessment of culturally and linguistically diverse children and adolescents: A practitioner's guide. New York, NY: Springer.

Geva, E., Wade-Woolley, L., \& Shany, M. (1993). The concurrent development of spelling and decoding in two different orthographies. Journal of Literacy Research, 25, 383-406.

Geva, E., \& Yaghoub Zadeh, Z. (2006). Reading efficiency in native English-speaking and English-as-asecond-language children: The role of oral proficiency and underlying cognitive-linguistic processes. Scientific Studies of Reading, 10, 31-57. 
Hale, J., Alfonso, V., Berninger, V., Bracken, B., Christo, C., Clark, E., ... Yalof, J. (2010). Critical issues in response-to-intervention, comprehensive evaluation, and specific learning disabilities identification and intervention: An expert white paper consensus. Learning Disability Quarterly, 33, 223-236.

Harrison, G. L., Goegan, L. D., Jalbert, R., McManus, K., Sinclair, K., \& Spurling, J. (2016). Predictors of spelling and writing skills in first- and second-language learners. Reading and Writing, 29, 69-89.

Hassin, R. R., Bargh, J. A., Engell, A. D., \& McCulloch, K. C. (2009). Implicit working memory. Consciousness and Cognition, 18, 665-678.

Helland, T., \& Kaasa, R. (2005). Dyslexia in English as a second language. Dyslexia, 11, 41-60.

Kendeou, P., van den Broek, P., Helder, A., \& Karlsson, J. (2014). A cognitive view of reading comprehension: implications for reading difficulties. Learning Disabilities Research \& Practice, 29, 10-16.

Kirby, J. R., Georgiou, G. K., Martinussen, R., \& Parrila, R. (2010). Naming speed and reading: From prediction to instruction. Reading Research Quarterly, 45, 341-362.

Koda, K. (2007). Reading and language learning: Crosslinguistic constraints on second language reading development. Language Learning, 57(1), 1-44.

Kormos, J. (2017). The second language learning processes of students with specific learning difficulties. New York, NY: Routledge.

Kormos, J., \& Csizér, K. (2010). A comparison of the foreign language learning motivation of Hungarian dyslexic and non-dyslexic students. International Journal of Applied Linguistics, 20, 232-250.

Kormos, J., \& Kontra, E. H. (2008) (Eds.), Language learners with special needs: An international perspective. Clevedon, UK: Multilingual Matters.

Kormos, J., \& Mikó, A. (2010). Diszlexia és az idegen-nyelvtanulás folyamata [Dyslexia and the process of second language acquisition]. In J. Kormos \& K. Csizér (Eds.), Idegennyelv-elsajátítás és részképességzavarok [Foreign language acquisition and learning disabilities] (pp. 49-76). Budapest, Hungary: Eötvös Kiadó.

Kormos, J., \& Smith, A.-M. (2012). Teaching languages to students with specific learning differences. Bristol, UK: Multilingual Matters.

Landerl, K., Ramus, F., Moll, K., Lyytinen, H., Leppanen, P., Lovansuu, K., ... Schulte-Körne, G. (2013). Predictors of developmental dyslexia in European orthographies with varying complexity. Journal of Child Psychology and Psychiatry, 54, 686-694.

Landerl, K., \& Wimmer, H. (2008). Development of word reading fluency and spelling in a consistent orthography: An 8-year follow-up. Journal of Educational Psychology, 100, 150-161.

Lesaux, N. K., \& Siegel, L. S. (2003). The development of reading in children who speak English as a second language. Developmental Psychology, 39, 1005-1019.

Limbos, M. M., \& Geva, E. (2001). Accuracy of teacher assessments of second-language students at risk for reading disability. Journal of Learning Disabilities, 34, 136-151.

Linck, J. A., Osthus, P., Koeth, J. T., \& Bunting, M. F. (2014). Working memory and second language comprehension and production: A meta-analysis. Psychonomic Bulletin \& Review, 21, 861-883.

Lovett, M. W., Steinbach, K. A., \& Frijters, J. C. (2000). Remediating the core deficits of developmental reading disability: A double-deficit perspective. Journal of Learning Disabilities, 33, 334-358.

Martin, K. I., \& Ellis, N. C. (2012). The roles of phonological STM and working memory in L2 grammar and vocabulary learning. Studies in Second Language Acquisition, 34, 379-413.

Melby-Lervåg, M., \& Lervåg, A. (2014). Reading comprehension and its underlying components in second-language learners: A meta-analysis of studies comparing first- and second-language learners. Psychological Bulletin, 140, 409-430.

Ndlovu, K., \& Geva, E. (2008). Writing abilities in first and second language learners with and without reading disabilities. In J. Kormos \& E. H. Kontra (Eds.), Language learners with special needs: An international perspective (pp. 36-62) Clevedon, UK: Multilingual Matters.

Norwich, B. (2009). How compatible is the recognition of dyslexia with inclusive education?. In G. Reid (Ed.), The Routledge companion to dyslexia (pp. 177-193). London, UK: Routledge.

Olkkonen, S. (2013). Speed in cognitive tasks as an indicator of second/foreign language reading and writing skills. Estonian Papers in Applied Linguistics, 9, 195-208.

Perfetti, C. (2007). Reading ability: Lexical quality to comprehension. Scientific Studies of Reading, 8, 293-304.

Perfetti, C. A., \& Harris, L. N. (2013). Universal reading processes are modulated by language and writing system. Language Learning and Development, 9, 296-316. 
Perfetti, C. A., Zhang, S., \& Berent, I. (1992). Reading in English and Chinese: Evidence for a "universal" phonological principle. In R. Frost \& L. Katz (Eds.), Orthography, phonology, morphology, and meaning (pp. 227-248). Amsterdam, The Netherlands: North-Holland.

Piechurska-Kuciel, E. (2008). Input, processing and output anxiety in students with symptoms of developmental dyslexia. In J. Kormos \& E. H. Kontra (Eds.), Language learners with special needs. An international perspective (pp. 86-109). Bristol, UK: Multilingual Matters.

Ravid, D., \& Malenky, D. (2001). Awareness of linear and nonlinear morphology in Hebrew: A developmental study. First Language, 21, 25-56.

Reber, A. S., Walkenfeld, F. F., \& Hernstadt, R. (1991). Implicit and explicit learning: Individual differences and IQ. Journal of Experimental Psychology: Learning, Memory, and Cognition, 17, 888-896.

Saeigh-Haddad, E., \& Geva, E. (2008). Morphological awareness, phonological awareness, and reading in English-Arabic bilingual children. Reading and Writing: An Interdisciplinary Journal, 21, 481504.

Samson, J. F., \& Lesaux, N. K. (2009). Language-minority learners in special education: Rates and predictors of identification for services. Journal of Learning Disabilities, 42, 248-162.

Sarkadi, Á. (2008). Vocabulary learning in dyslexia-The case of a Hungarian learner. In J. Kormos \& E. H. Kontra (Eds.), Language learners with special needs: An international perspective (pp. 110-129). Clevedon, UK: Multilingual Matters.

Schoonen, R., Snellings, P., Stevenson, M., \& van Gelderen, A. (2009). Towards a blueprint of the foreign language writer: The linguistic and cognitive demands of foreign language writing. In R. M. Manchon (Ed.), Writing in foreign language contexts: Learning, teaching and research (pp. 77-101). Bristol, UK: Multilingual Matters.

Service, E. (1992). Phonology, working memory and foreign language learning. Quarterly Journal of Experimental Psychology, 45(1), 21-50.

Service, E., \& Kohonen, V. (1995). Is the relation between phonological memory and foreign language learning accounted for by vocabulary acquisition? Applied Psycholinguistics, 16, 155-172.

Smith, A.-M. (2013). Developing cognitive assessments for multilingual learners. In D. Tsagari \& G. Spanoudis (Eds.), Assessing L2 students with learning and other disabilities (pp. 151-168). Newcastle upon Tyne, UK: Cambridge Scholars.

Sparks, R. L., Artzer, M., Patton, J., Ganschow, L., Miller, K., Hordubay, D. J., \& Walsh, G. (1998). Benefits of multisensory structured language instruction for at-risk foreign language learners: A comparison study of high school Spanish students. Annals of Dyslexia, 48, 239-270.

Sparks, R. L., \& Ganschow, L. (1993). The impact of native language learning problems on foreign language learning: Case study illustrations of the linguistic coding deficit hypothesis. Modern Language Journal, 77, 58-74.

Sparks, R., \& Ganschow, L. (2001). Aptitude for learning a foreign language. Annual Review of Applied Linguistics, 21, 90-111.

Sparks, R. L., Javorsky, J., Ganschow, L., Pohlman, J., \& Patton, J. (1992). Test comparisons among students identified as high-risk, low-risk, and learning disabled in high school foreign language courses. The Modern Language Journal, 76, 142-159.

Stanovich, K. E. (1988). Explaining the differences between the dyslexic and the garden-variety poor reader: The phonological-core variable-difference model. Journal of Learning Disabilities, 21, 590604.

Stoodley, C. J., Harrison, E. P., \& Stein, J. F. (2006). Implicit motor learning deficits in dyslexic adults. Neuropsychologia, 44(5), 795-798.

Thomas, G., \& Loxley, A. (2007). Deconstructing special education. Maidenhead, UK: Open University Press.

Unsworth, N., \& Engle, R. W. (2005). Working memory capacity and fluid abilities: Examining the correlation between operation span and raven. Intelligence, 33, 67-81.

Vellutino, F. R. (1979). Dyslexia: Theory and research. Cambridge MA: MIT Press.

Wang, X., Georgiou, G. K., Das, J.P., \& Li, Q. (2012). Cognitive processing skills and developmental dyslexia in Chinese. Journal of Learning Disabilities, 45, 526-537.

Wolf, M., \& Bowers, P. G. (1999). The double deficit hypothesis for the developmental dyslexias. Journal of Educational Psychology, 91, 1-24.

Ziegler, J. C., Bertrand, D., Tóth, D., Csépe, V., Reis, A., Faísca, L., Saine, N., ... Blomert, L. (2010). Orthographic depth and its impact on universal predictors of reading: A cross-language investigation. Psychological Science, 21, 551-559. 